\title{
Preparation of Cotton Fibers Modified With Aromatic Heterocyclic Compounds and Study of $\mathrm{Cr}(\mathrm{Vl})$ Adsorption Performance
}

\section{Zhiyu Huang}

Wuhan Textile University

\section{Peng Wu}

Third Institute of Oceanography Ministry of Natural Resources

\section{Yankun Yin}

Wuhan Textile University

\section{Xiang Zhou}

Wuhan Textile University

Lu Fu

Wuhan Textile University

\section{Luoxin Wang}

Wuhan Textile University

shaohua chen ( $\nabla$ shaohuachen@foxmail.com )

Wuhan Textile University https://orcid.org/0000-0002-0274-2089

\section{Xu Tang}

Third Institute of Oceanography Ministry of Natural Resources

\section{Research Article}

Keywords: Degreasing cotton, Chromium, Adsorption, Aminopyridine, Aminopyrazine, Surface modification

Posted Date: May 25th, 2021

DOl: https://doi.org/10.21203/rs.3.rs-510086/v1

License: (c) (1) This work is licensed under a Creative Commons Attribution 4.0 International License. Read Full License 


\section{Preparation of cotton fibers modified with aromatic}

2 heterocyclic compounds and study of $\mathrm{Cr}$ (VI) adsorption

3 performance

Zhiyu Huang ${ }^{\mathrm{a}, 1}$, Peng Wu ${ }^{\mathrm{b}, 1}$, Yankun Yin ${ }^{\mathrm{a}}$, Xiang Zhou ${ }^{\mathrm{a}}$, Lu Fu ${ }^{\mathrm{a}}$, Luoxin Wang ${ }^{\mathrm{a}}$,

Shaohua Chen ${ }^{\mathrm{a}, *}, \mathrm{Xu}$ Tang $^{\mathrm{b}, * *}$

$6 \quad$ Key Laboratory of Textile Fibers and Products, Ministry of Education, P. R. C, College

7 of Materials Science and Engineering, Wuhan Textile University, Wuhan 430200,

8 China

$9{ }^{\mathrm{b}}$ Third Institute of Oceanography Ministry of Natural Resources, P. R. C, Xiamen

$10 \quad 361005$, China

$11{ }^{*}$ Corresponding author.

$12{ }^{* *}$ Corresponding author.

$13 \quad{ }^{1}$ Zhiyu Huang and Peng Wu as co-first author contributed equally to this work

14 Corresponding author:, Shaohua Chen ${ }^{\mathrm{a},{ }^{*}}$ and $\mathrm{Xu} \mathrm{Tang}^{\mathrm{b},{ }^{, * *}}$

15 Email: shaohuachen@,foxmail.com (S.H.C), tangxu@tio.org.cn (X. T)

\section{ABSTRACT:}

In order to prepare low-cost and environmentally friendly adsorbent materials for adsorption of heavy metal ion, two kinds of novel modified cottons (C-4-APD and C2-APZ) were obtained by introducing 4-aminopyridin and 2-aminopyrazine into the surface of degreasing cotton, respectively, and used for the removal of $\mathrm{Cr}(\mathrm{VI})$ ions from aqueous solution. The two modified cottons were characterized by Scanning Electron Microscopy (SEM), Fourier Transform Infrared Spectroscopy (FTIR) and X-ray 
1 photoelectron spectroscopy (XPS), which confirmed the amino groups, pyridine groups

2 and pyrazine groups grafted onto the surface of modified cottons. The maximum

3 adsorption capacities of C-4-APD and C-2-APZ were $73.78 \mathrm{mg} / \mathrm{g}$ and $61.34 \mathrm{mg} / \mathrm{g}$,

4 respectively, at the optimum $\mathrm{pH}$ of 6 and an initial concentration of $200 \mathrm{mg} / \mathrm{g}$. Kinetic

5 and isotherm studies were carried out to investigate the adsorption behavior of the

6 modified cottons on $\mathrm{Cr}(\mathrm{VI})$ ions. The results showed that the adsorption of $\mathrm{Cr}(\mathrm{VI})$ ions

7 by modified cottons followed a pseudo-second-order kinetic model, the equilibrium

8 data were in good agreement with the Langmuir isotherm model, and electrostatic and

9 chemisorption may be the main adsorption mechanisms. The recovery and reuse of

10 modified cotton were achieved by washing with $2 \mathrm{wt} \%$ thiourea-hydrochloric acid

11 solution $(0.5 \mathrm{~mol} / \mathrm{L}$ concentration of $\mathrm{HCl})$, and the adsorption capacities of C-4-APD

12 and C-2-APZ were maintained above $90 \%$ and $80 \%$, respectively, after six cycles.

13 Keywords: Degreasing cotton; Chromium; Adsorption; Aminopyridine;

14 Aminopyrazine; Surface modification

\section{Introduction}

The presence of chromium in the environment is generally $\mathrm{Cr}(\mathrm{III})$ and $\mathrm{Cr}(\mathrm{VI})$. Trace amounts of $\mathrm{Cr}$ (III) can reduce the blood glucose concentration in the human body to a certain extent, accelerate the metabolic process of sugar and substances required by the body, and the human insulin activity and stress response capacity can also be regulated by $\mathrm{Cr}(\mathrm{III})($ Kooshki et al. 2021, Moradi et al. 2019). $\mathrm{Cr}$ (VI) has higher mobility, bioavailability and carcinogenic effect, and is 100 times more toxic than

$22 \mathrm{Cr}(\mathrm{III})$, which can cause more serious harm to various organisms(Kimbrough et al. 
11999 , Singh and Chowdhuri 2017). At present, the main methods for treating

2 chromium-containing wastewater are adsorption(Sun et al. 2021), chemical(Bao et al.

3 2020), ion exchange( $\mathrm{Li}$ et al. 2017), electrochemical(Yao et al. 2020) and biological

4 methods(Long et al. 2020), etc. The most industrial application is adsorption method,

5 which is suitable for the deep purification of low concentration chromium-containing

6 wastewater because of its simplicity and convenience(Zhao et al. 2015). However, most

7 of the adsorbents reported in the literature for the removal of hexavalent chromium are

8 prepared under complicated process conditions, raw materials are not easily available,

9 costs are high, and they are also difficult to degrade in the natural environment, which may cause secondary pollution to the environment in practical applications.

Biomass materials are widely available, relatively low-priced, with large specific surface area, good stability and biodegradable, etc. At the same time, the surface of biomass materials is rich in hydroxyl groups and other reactive groups, which can be regulated and functionalized by chemical or physical methods, and are ideal choices for carrier materials(Xu et al. 2016), such as cellulose(Park et al. 2020, Sharma et al. 2018), lignin(Wu et al. 2008), hemicellulose(Wei et al. 2021), chitosan(Vakili et al. 2018 , Eliodorio et al. 2017), etc. Highly efficient adsorbents were prepared by grafting the cellulose with functional groups(Zhang et al. 2019, Xie et al. 2017, Li et al. 2018), Liang et al. (2020) reported the maximum $\mathrm{Cr}(\mathrm{VI})$ uptake was $490.3 \mathrm{mg} / \mathrm{g}$ for quaternized cellulose grafted with polyethyleneimine in the presence of epichlorohydrin. The imidazole groups were successfully grafted onto the macroporous cellulose by a homogeneous method to fabricate $3 \mathrm{D}$ macroporous materials with 
1 synergistic advantages of cellulose and polyvinylimidazole, and the optimized

2 adsorbent exhibited a fast adsorption rate $(0.12 \mathrm{~g} /(\mathrm{mg} / \mathrm{min}))$ and high adsorption

3 capacity $(134 \mathrm{mg} / \mathrm{g})($ Peng et al. 2020). However, for crude processed biomass materials

4 such as cotton, hemp, and agricultural wastes, the corresponding reports are less

5 available and have a low $\mathrm{Cr}(\mathrm{VI})$ adsorption capacity. For example, Rojas et al. (2018)

6 reported the removal of $\mathrm{Cr}(\mathrm{VI})$ from water using cotton fibers coated with deacetylated

7 chitosan, and the adsorption capacity for $\mathrm{Cr}(\mathrm{VI})$ was $7.5 \mathrm{mg} / \mathrm{g}$ at $\mathrm{pH} 2.0$. The crude

8 processed biomass material is more widely available and if it is utilized to improve and

9 increase its adsorption capacity for $\mathrm{Cr}(\mathrm{VI})$, the processing steps for preparing biomass-

10 based adsorbents can be more simplified and less costly.

11 Pyridines and pyrazines are important intermediate compounds that are widely

12 used in the synthesis of medical (agricultural) drugs and in the preparation of dyes, and

13 they can also be used as drugs and analytical reagents themselves. However, there are

14 few reports on the use of pyridines and pyrazines for contaminant treatment. By

15 electron-donating nitrogen, as well as electron-rich $\pi$-conjugated structures, and the

16 nitrogen atoms in pyridine group and pyrazine group form hydrogen bonds, so the

17 polymer containing pyridine group or pyrazine group has the ability of coordination

18 chelation, which can be used for the removal of metal ions in solution and

19 environmental pollution control. Geng et al. (2020) reported that two kinds of

20 fluorescent conjugated microporous polymers containing pyrazine moieties were

21 prepared by the polymerization reaction of 2,5-di-triphenylamine-yl-pyrazine(DTPAPz)

22 and N,N,N',N'-tetrapheny-2,5-(diazyl) pyrazine (TDPz), for adsorbing and fluorescent 
1 sensing of iodine. Bayramoglu et al. (2016) reported that aminopyridine modified

2 Spirulina platensis biomass for $\mathrm{Cr}(\mathrm{VI})$ adsorption in aqueous solution. chemical

3 modification of Spirulina platensis biomass was realized by sequential treatment of

4 algal surface with epichlorohydrin and aminopyridine. The adsorption capacity at $\mathrm{pH}$

$5 \quad 3.0$ was found to be 79.6 and $158.7 \mathrm{mg} / \mathrm{g}$, for native and modified algal biomasses,

6 respectively. It is clear from these studies that pyridines and pyrazines have good

7 potential for the treatment of heavy metal ions and other contaminants.

Therefore, in order to further reduce costs and prepare environmentally friendly

9 adsorbent materials, 4-aminopyridine and 2-aminopyrazine were introduced to the

10 surface of degeasing cotton using one-pot method in this study. The cotton-4-

11 aminopyridine(C-4-APD) and the cotton-2-aminopyrazine(C-2-APZ) were obtained

12 and used for the removal of $\mathrm{Cr}(\mathrm{VI})$ ions from aqueous medium. The morphology and

13 structure property of the prepared samples were characterized by the SEM, FTIR and

14 XPS. Additionally, the adsorption behavior of Cr(VI) on C-4-APD and C-2-APZ was

15 investigated by Langmuir and Freundlich models, and the experimental data were fitted

16 by two kinetic models, pseudo-first-order and pseudo-second-order(Simonin 2016), to

17 analyze the mechanism of $\mathrm{Cr}(\mathrm{VI})$ adsorption, and its reusability was evaluated by

18 repeated adsorption-elution, and the modification effect of the two groups on cotton

19 fibers was also compared.

\section{Experiment}

\subsection{Materials}

22 Potassium chromate( $99.9 \%$ metals basis), 4-aminopyridin(98\%) and 2- 
1 aminopyrazine(99\%) were purchased from Shanghai Macklin Biochemical Co.,

2 Ltd(Shanghai, China). Epichlorohydrin, N,N-dimethylformamide (DMF), hydrochloric

$3 \operatorname{acid}(30 \%)$ and thiourea(AR 99\%) were purchased from Sinopharm Chemical Reagent

4 Corp (Shanghai, China). Degreasing cotton was supplied from Xuzhou Weicai Hygiene

5 of Material Factory Co. LTD (Xuzhou, China).

\subsection{Preparation of cotton-4-aminopyridin and cotton-2-aminopyrazine}

$71 \mathrm{~g}$ of degreasing cotton was soaked in the solvent of $50 \mathrm{~mL}$ of $\mathrm{N}, \mathrm{N}-$

8 dimethylformamide and $50 \mathrm{~mL}$ of epichlorohydrin to soak. In the first stage, the

9 reaction temperature was controlled at $80{ }^{\circ} \mathrm{C}$, and the chloromethylated skimmer was

10 stirred slowly for $2 \mathrm{~h}$ with a magnetic stirrer to obtain chloromethylated degreasing

11 cotton; In the second stage, $10 \mathrm{mmol}$ of 4-aminopyridin or 2-aminopyrazine was

12 accurately added to the above solution. The mixture continued to be stirred for $5 \mathrm{~h}$ at

$1390{ }^{\circ} \mathrm{C}$. The procedure for preparation of C-4-APD/C-2-APZ is illustrated in Fig. 1.
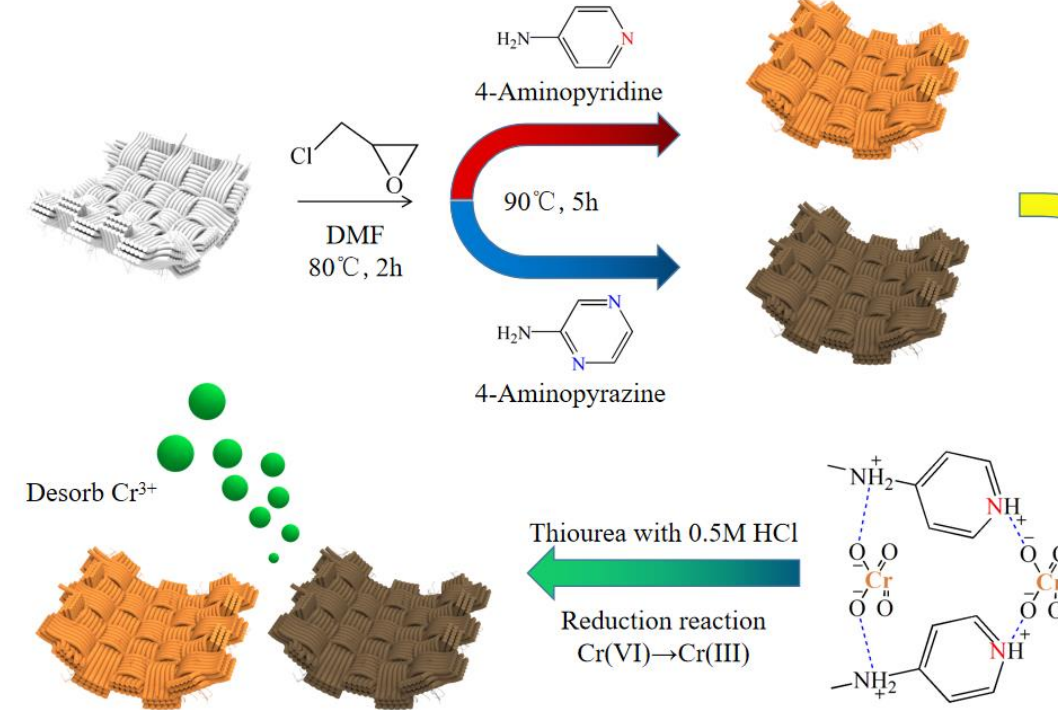
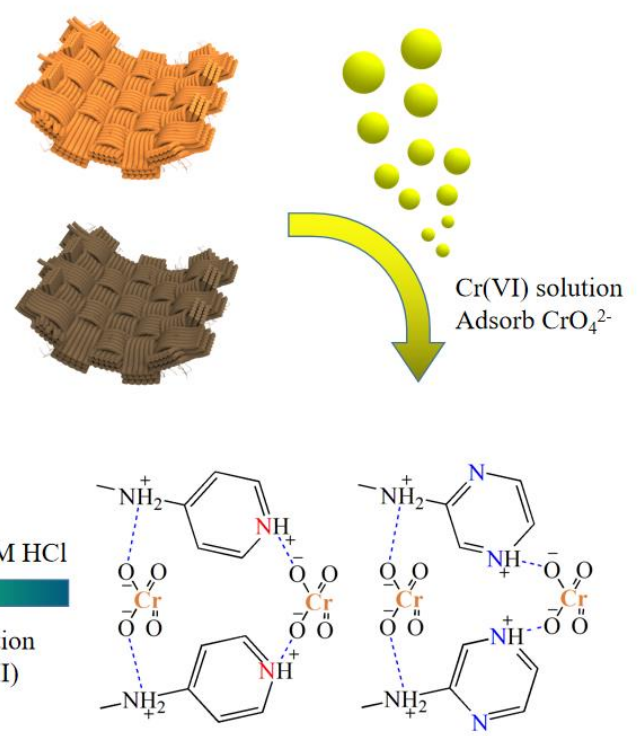

Fig.1 Schematic illustration of the C-4-APD and C-2-APZ preparation process.

\subsection{Characterization}


1 Surface morphological characteristics of degreasing cotton, C-4-APD and C-2-APZ

2 were examined by scanning electron microscopy (SEM) using a JSM-IT300A scanning

3 electron microscope(JEOL Ltd.,Tokyo, Japan). Bonding structure and surface

4 functionalization of samples were conducted on a VERTEX 70 FT-IR spectrometer by

5 using potassium bromide pressed-disk technique, respectively. The scan range was 400

6 to $4000 \mathrm{~cm}^{-1}$. The elemental composition of the samples was measured by XPS using

7 Thermo Scientific K-Alpha (Thermo Fisher).

\subsection{Adsorption experiments}

The effect of $\mathrm{pH}$ of the reaction system on the $\mathrm{Cr}(\mathrm{VI})$ adsorption capacity brought by C-4-APD and C-2APZ in Cr(VI) adsorption experiments, as well as their adsorption thermodynamics, adsorption kinetics, and recyclability were investigated by a series of adsorption experiments. All Cr(VI) adsorption experiments were performed in $150 \mathrm{~mL}$ beakers at room temperature and shaken at $120 \mathrm{rpm}$ in a mechanical shaker. To explore the effect of $\mathrm{pH}$ on the $\mathrm{Cr}(\mathrm{VI})$ adsorption capacity, $0.16 \mathrm{~g}$ of C-4-APD/C-2-APZ was placed into $100 \mathrm{ml}$ of $100 \mathrm{mg} / \mathrm{L} \mathrm{Cr}(\mathrm{VI})$ solution with different $\mathrm{pH}$ values. The $\mathrm{pH}$ was adjusted by concentrations of $0.5 \mathrm{M}$ and $1 \mathrm{M}$ hydrochloric acid. $\mathrm{Cr}(\mathrm{VI})$ concentrations were determined by ICP 2060T inductively coupled plasma emission spectrometer (Jiangsu Tianrui Instruments Co., Ltd., Kunshan, China), and the adsorption capacity of modified cotton for $\mathrm{Cr}(\mathrm{VI})$ was calculated as follows:

$Q=\frac{\left(C_{0}-C_{\mathrm{e}}\right) \times V}{\mathrm{~m}}$

where $\mathrm{C}_{0}$ and $\mathrm{C}_{\mathrm{e}}(\mathrm{mg} / \mathrm{L})$ are the initial concentration and the equilibrium concentration of $\mathrm{Cr}(\mathrm{VI}), \mathrm{V}(\mathrm{L})$ is the volume of $\mathrm{Cr}(\mathrm{VI})$ solution, and $\mathrm{m}(\mathrm{mg})$ is the mass of the 
absorbent.

\section{Results and discussion}

\subsection{Characterization of the samples}

Fig.2 shows the scanning electron micrographs of degreasing cotton, C-4-APD and C-2-APZ. The surface of the degeasing cotton fiber was smooth and the diameter of the cotton fiber was about $15 \mathrm{um}$ as seen in Fig. 1A. From Fig. 1B and Fig. 1C, it was observed that the surfaces of both C-4-APD and C-2-APZ become rough, indicating that organic monomers are grafted on the surface of cotton fibers.
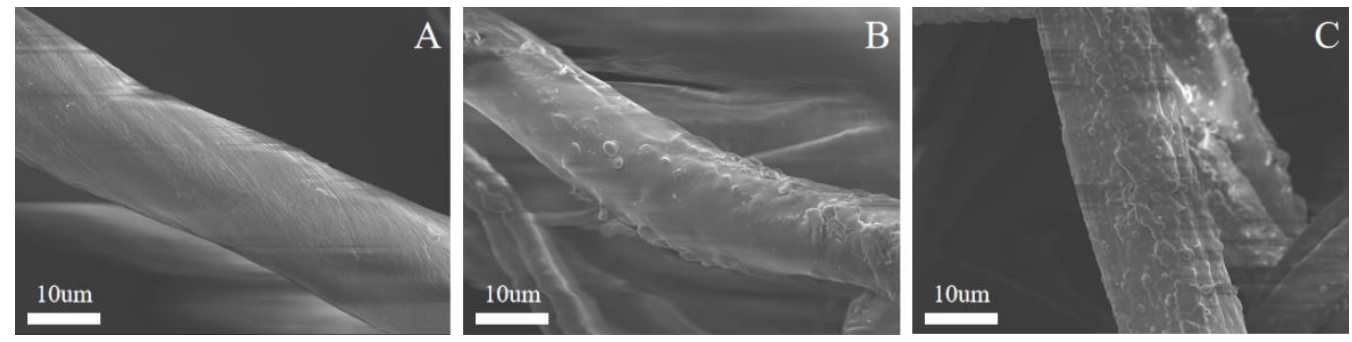

Fig.2 SEM images of the degreasing cotton (A), C-4-APD (B) and C-2-APZ (C).

Fig.3 shows the FTIR spectra of degreasing cotton, C-4-APD and C-2-APZ. The FTIR profiles of skimmed cotton: the peaks at $3315 \mathrm{~cm}^{-1}$ are caused by stretching vibrations due to the presence of a large number of hydroxyl hydrogen bonds in the cotton fiber; the peaks at $1407 \mathrm{~cm}^{-1}$ and $1303 \mathrm{~cm}^{-1}$ are caused by the bending vibrations of $\mathrm{CH}_{2}$ and $\mathrm{CH}$ present in large quantities in the cellulose backbone structure, respectively; the characteristic absorption bands at $1149 \mathrm{~cm}^{-1}$ and $1019 \mathrm{~cm}^{-1}$ are each The characteristic absorption bands at $1149 \mathrm{~cm}^{-1}$ and $1019 \mathrm{~cm}^{-1}$ are each attributed to the asymmetric stretching vibration of C-O-C and the stretching vibration of C-O in the cellulose six-membered ring structure(Wang et al. 2019). After attachment of 4aminopyridine/2-aminopyrazine via epichlorohydrin coupling reaction, the spectrum of 
1 the modified degreasing cotton exhibits some changes. The peak formed at $3244 \mathrm{~cm}^{-1}$

2 was an N-H stretching vibration peak in the imine group(Bayramoglu et al. 2016).

3 Besides, the new characteristic peaks observed at $1643 \mathrm{~cm}^{-1}, 1638 \mathrm{~cm}^{-1}$, and $1543 \mathrm{~cm}^{-1}$

4 are caused by $\mathrm{C}=\mathrm{N}$ and $\mathrm{C}-\mathrm{N}$ bonds in the aromatic heterocycles, confirming the

5 successful grafting of pyridine and pyrazine groups on the degreasing cotton surface(Hu

6 et al. 2014 , Lu et al. 2020).

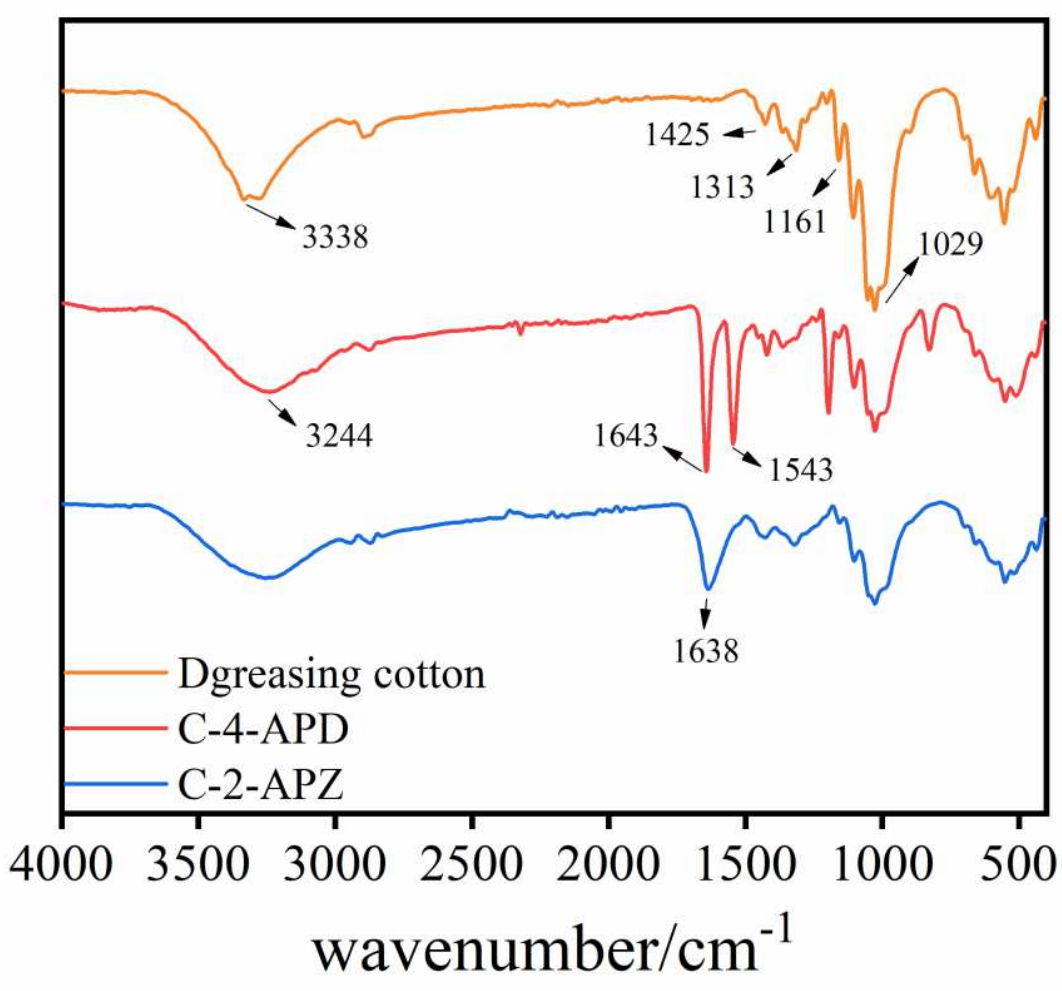

Fig. 3 FTIR spectra of degreasing cotton, C-4-APD and C-2-APZ.

The mass fraction of elements of the degreasing cotton, C-4-APD and C-2-APZ were determined using XPS to study the amount of aromatic heterocyclic compounds introduced. As shown in Table 1, the degreasing cotton contains almost no elemental N. After grafting the 4-aminopyridine and 2-aminopyrazine onto the surface of the degreasing cotton, the $\mathrm{N}$ elemental content of C-4-APD and C-2-APZ increased 
1 significantly, which further proved the successful introduction of 4-aminopyridine and

2 2-aminopyrazine on the surface of degreasing cotton.

3 Table 1 The mass fraction of elements of degreasing cotton, C-4-APD and C-2-APZ.

\begin{tabular}{cccc}
\hline materials & $\mathrm{C} / \%$ & $\mathrm{~N} / \%$ & $\mathrm{O} / \%$ \\
\hline Dgreasing cotton & 70.83 & 0.59 & 28.58 \\
C-4-Aminopyridine & 69.7 & 5.52 & 24.78 \\
C-2-Aminopyrazine & 65.28 & 9.69 & 25.03 \\
\hline
\end{tabular}

$4 \quad$ 3.2. Batch adsorption studies

5

\subsubsection{Effect of $\mathrm{pH}$}

Fig.4 shows the difference in the adsorption capacity of C-4-APD and C-2-APZ for $\mathrm{Cr}(\mathrm{VI})$ in the range of solution $\mathrm{pH}$ from 2 to 8 , with an adsorption time of $4 \mathrm{~h}$. In aqueous media, $\mathrm{Cr}(\mathrm{VI})$ ions exist mainly as soluble oxides, and the ionic species depend on the $\mathrm{pH}$ of the medium and the total concentration of $\mathrm{Cr}(\mathrm{VI})$ in the solution, when the solution $\mathrm{pH}$ is less than 2.0, the dominant species is $\mathrm{H}_{2} \mathrm{CrO}_{4}$. When the solution $\mathrm{pH}$ is greater than 7.0, only $\mathrm{CrO}_{4}{ }^{2-}$ is present, while the solution $\mathrm{pH}$ is between 2.0 and 6.0, $\mathrm{HCrO}^{4-}$ and $\mathrm{Cr}_{2} \mathrm{O}_{7}^{2-}$ dominate(Bayramoglu et al. 2016). It can be seen from graphs that the adsorption of $\mathrm{Cr}(\mathrm{VI})$ by $\mathrm{C}-4-\mathrm{APD}$ and $\mathrm{C}-2-\mathrm{APZ}$ increases as the $\mathrm{pH}$ decreases, which mainly due to the $\mathrm{N}$ atoms in the pyridine, pyrazine and imine groups are prone to binding $\mathrm{H}+$ under acidic conditions leading to protonation and gravitational binding between them and the negatively charged $\mathrm{Cr}(\mathrm{VI})$ anion, resulting in an increase in the removal efficiency of $\mathrm{Cr}(\mathrm{VI})$. As shown in Fig.4, the adsorption capacity of the former was higher than that of the latter, which was due to the different electron cloud distribution of the $\mathrm{N}$ atoms between the 4-aminopyridin and 2-aminopyrazine. The $\mathrm{N}$ atoms of the pyridine group in 4-aminopyridin are in the opposite position of the amino 
1 group, which have stronger ability to bind $\mathrm{H}^{+}$when protonated, while the $\mathrm{N}$ atoms of

2 pyrazine group in 2-aminopyrazine are in the adjacent and interposition of amino group,

3 respectively, of which the electron cloud distribution was more dispersed, and the

4 ability of binding $\mathrm{H}^{+}$was weaker when protonated. At the solution $\mathrm{pH}$ less than 2.0 , the

5 degreasing cotton skeleton started to be decomposed by corrosion, thus, it was

6 determined that the adsorption capacity of C-4-APD and C-2-APZ for Cr(VI) reached

7 the maximum at $\mathrm{pH}=2.0$, and the subsequent experiments were carried out at this $\mathrm{pH}$

8 value.

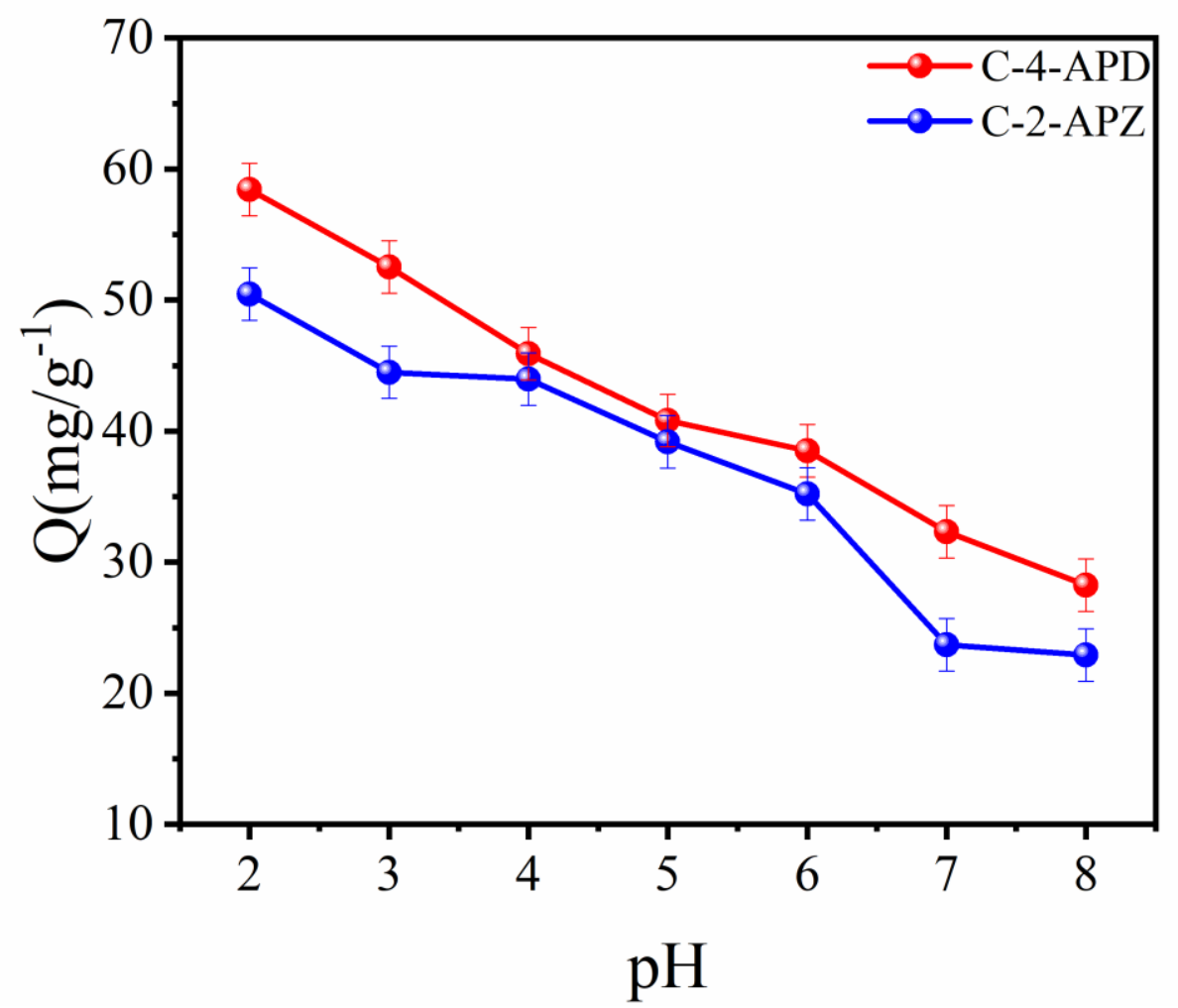

10 Fig. 4 Effect of the pH value on the adsorption of $\mathrm{Cr}(\mathrm{VI})$ ions by C-4-APD and C-2-APZ.

\section{$11 \quad 3.2 .2$. Adsorption kinetics}

Fig. 5A shows the effect of adsorption time on the $\mathrm{Cr}(\mathrm{VI})$ ions adsorption capacity 
1 capacity of $\mathrm{Cr}(\mathrm{VI})$ ions by $\mathrm{C}-2-\mathrm{APZ}$ increased faster, which was due to there are more

$2 \mathrm{~N}$ atomic sites on the surface of C-2-APZ than C-4-APD. With the increase of time, the

$3 \mathrm{~N}$ atomic sites slowly reached saturation, and the adsorption of $\mathrm{Cr}(\mathrm{VI})$ ions by the

4 adsorbent became very slow and basically reached the adsorption equilibrium state after

$54 \mathrm{~h}$ of adsorption in the solution.
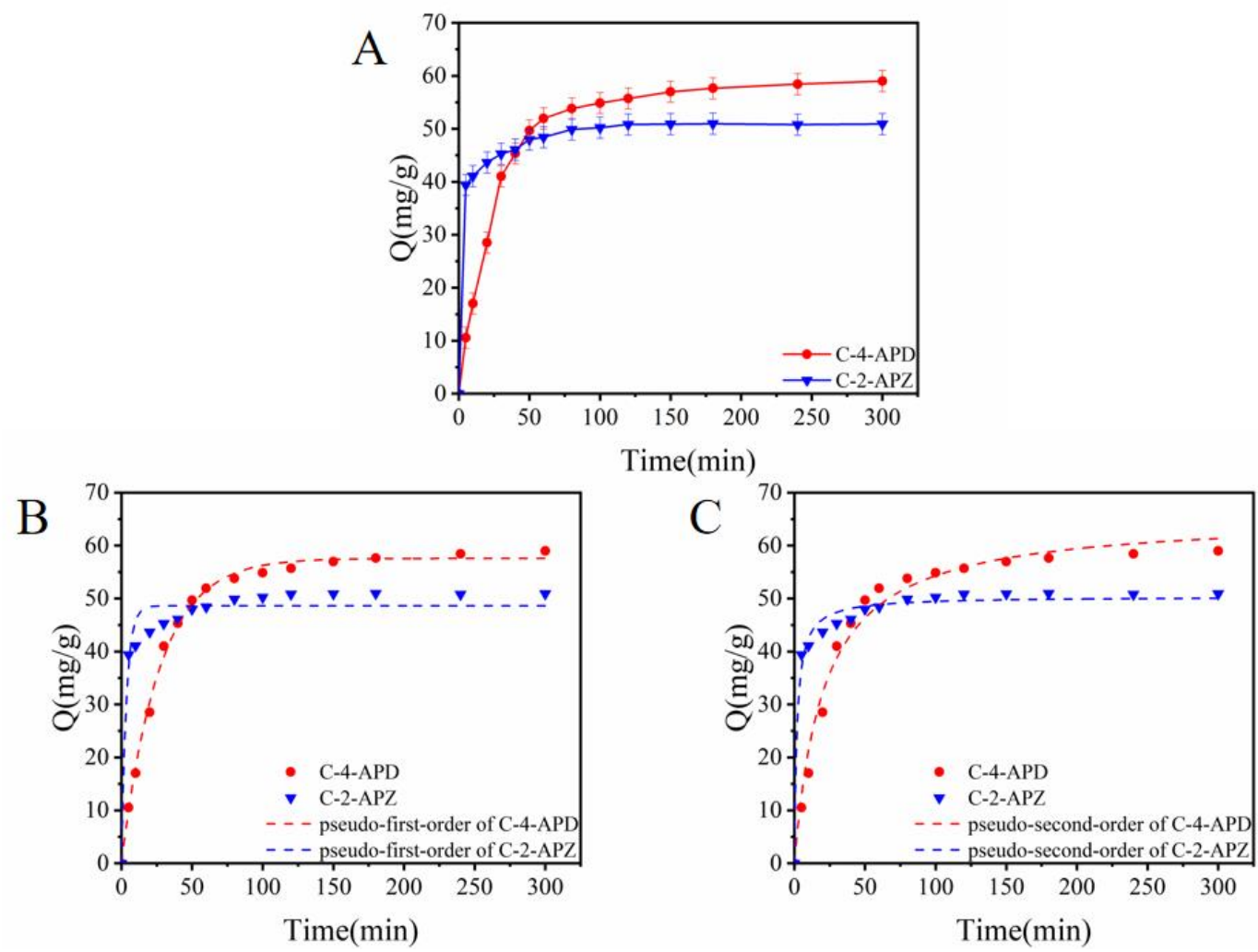

$7 \quad$ Fig. 5 Effect of contact time on the Cr(VI) ions adsorption capacity of C-4-APD and C-2-APZ(A); The curve fitting with pseudo-first-order(B) and pseudo-second-order kinetics model(C).

9 In order to investigate a range of kinetic factors for the adsorption of $\mathrm{Cr}(\mathrm{VI})$ ions by C-4-APD and C-2-APZ, pseudo-first-order and pseudo-second-order kinetic models

11 were used to fit the kinetic data:

$$
\ln \left(Q_{e}-Q_{t}\right)=\ln Q_{e}-k_{1} t
$$


$1 \quad \frac{\mathrm{t}}{Q_{t}}=\frac{1}{k_{2} Q_{e}^{2}}+\frac{1}{Q_{e}} t$

2 where $\mathrm{Q}_{\mathrm{e}}(\mathrm{mg} / \mathrm{g})$ and $\mathrm{Q}_{\mathrm{t}}(\mathrm{mg} / \mathrm{g})$ are the adsorption capacities of $\mathrm{Cr}(\mathrm{VI})$ ions at

3 equilibrium and time $\mathrm{t}(\mathrm{min})$ respectively; $\mathrm{k}_{1}\left(\min ^{-1}\right)$ and $\mathrm{k}_{2}((\mathrm{~g} / \mathrm{mg}) / \mathrm{min})$ are the

4 pseudo-first-order rate constant and pseudo-second-order rate constant, respectively.

Fig.5B and $\mathrm{C}$ are the fitted curves of the pseudo-first-order and pseudo-second-

6 order kinetic models for the actual experimental data of C-4-APD and C-2-APZ, and a

$7 \quad$ series of kinetic parameters calculated and fitted by the two adsorption equations are

8 shown in Table 2. As can be seen from the table, for C-4-APD, the correlation

9 coefficient R2 of the fitted curves of the pseudo-first-order model was higher than that

10 of the fitted curves of the pseudo-second-order model, which was as high as 0.996 .

11 However, since both the pseudo-second-order model fit the experimental data of C-4-

12 APD and C-2-APZ well, with correlation coefficients $\mathrm{R}^{2}$ of 0.983 and 0.986 ,

13 respectively, it was considered that C-4-APD and C-2-APZ for $\mathrm{Cr}(\mathrm{VI})$ ions follow the

14 pseudo-second-order model, and the rate of the adsorption process was influenced by

15 the physicochemical adsorption.

16 Table 2 Kinetic parameters for $\mathrm{Cr}$ (VI) ions uptake by C-4-APD and C-2-APZ.

\begin{tabular}{ccccccc}
\hline Absorbent & \multicolumn{3}{c}{ pseudo-first-order } & \multicolumn{3}{c}{ pseudo-second-order } \\
\hline & $\mathrm{Q}_{\mathrm{e}}(\mathrm{mg} / \mathrm{g})$ & $\mathrm{k}_{1}\left(\mathrm{~min}^{-1}\right)$ & $\mathrm{R}^{2}$ & $\mathrm{Q}_{\mathrm{e}}(\mathrm{mg} / \mathrm{g})$ & $\mathrm{k}_{2}((\mathrm{~g} / \mathrm{mg}) / \mathrm{min})$ & $\mathrm{R}^{2}$ \\
\cline { 2 - 7 } C-4-APD & 57.58 & 0.03773 & 0.996 & 65.57 & 0.00074 & 0.983 \\
C-4-APZ & 48.63 & 0.28318 & 0.954 & 50.37 & 0.01068 & 0.986 \\
\hline
\end{tabular}

17

18

19

\subsubsection{Adsorption isotherm}

Fig.6A shows the adsorption isotherms of Cr(VI) ions by C-4-APD and C-2-APZ.

It can be seen from the figure that the adsorption capacities of C-4-APD and C-2-APZ 
1 for $\mathrm{Cr}(\mathrm{VI})$ ions were almost the same at the initial concentration of $\mathrm{Cr}(\mathrm{VI})$ ions below

$260 \mathrm{mg} / \mathrm{L}$. However, as the initial concentration continued to increase, C-4-APD showed

3 better adsorption behavior, which also indicated that C-4-APD had better proton

4 binding ability. When the concentration of $\mathrm{Cr}(\mathrm{VI})$ ions solution increased to about 200

$5 \mathrm{mg} / \mathrm{L}$, the adsorption capacities of C-4-APD and C-2-APZ for $\mathrm{Cr}(\mathrm{VI})$ ions basically

6 ceased to change. The highest adsorption capacities of C-4-APD and C-2-APZ for

$7 \mathrm{Cr}(\mathrm{VI})$ ions were about $73.78 \mathrm{mg} / \mathrm{g}$ and $61.34 \mathrm{mg} / \mathrm{g}$, respectively. By comparing with

8 the maximum adsorption capacities of other surface modified biomass materials (Table

9 3), we can find that the adsorption capacities of C-4-APD and C-2-APZ were better, moreover, C-4-APD and C-2-APZ are very easy to separate from solution, compared

11 to high specific surface area of particulate or nanoparticle materials.
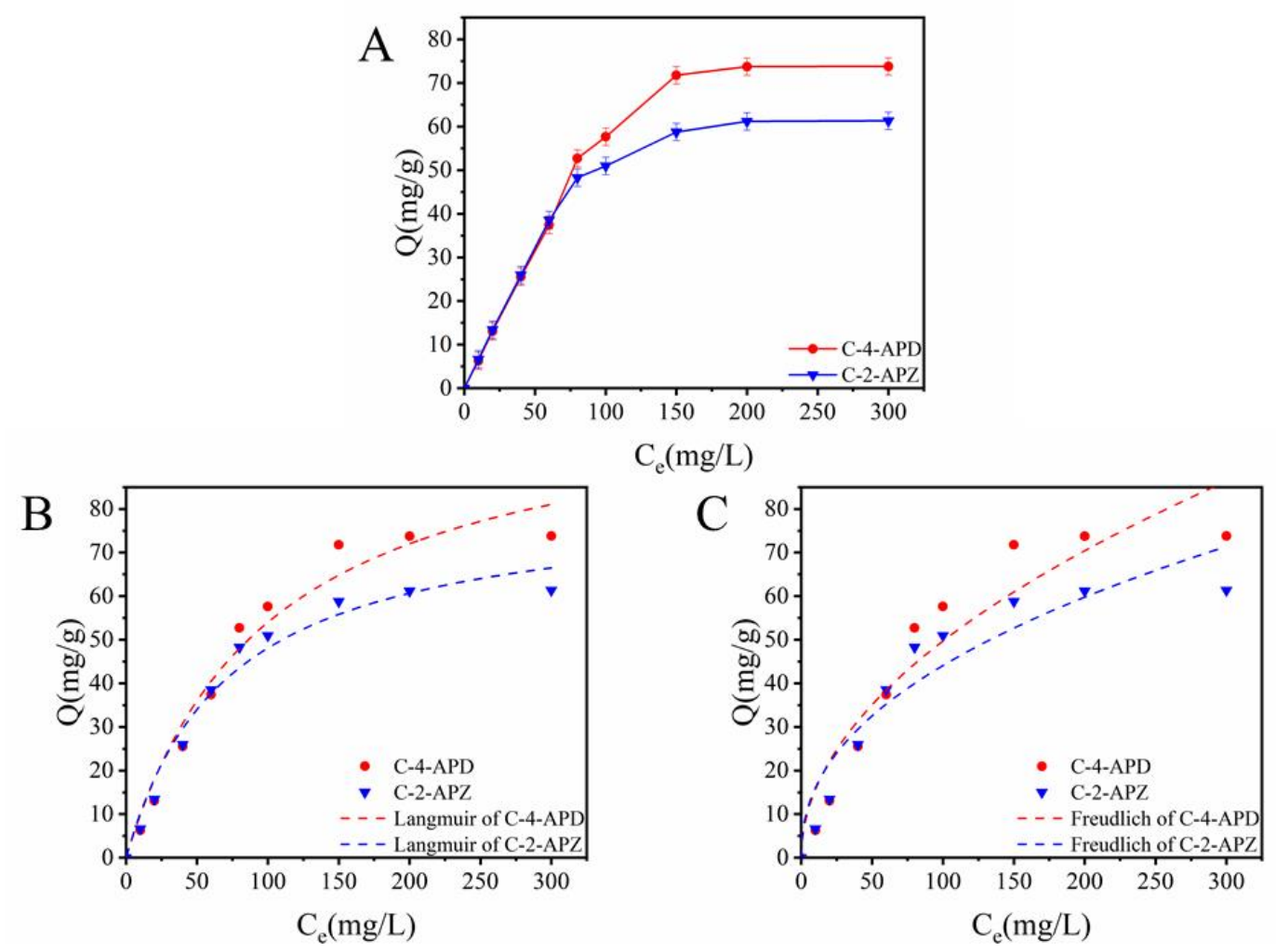

13 Fig. $6 \mathrm{Cr}(\mathrm{VI})$ ions adsorption isotherms for the C-4-APD and C-2-APZ(A); The curve fitting with 
the Langmuir(B) and Freundlich model(C).

Table 3 Comparison of adsorption capacities for $\mathrm{Cr}(\mathrm{VI})$ ions on various surface modified

3 biomass materials

\begin{tabular}{ccc}
\hline Adsorbents & $\begin{array}{c}\text { Adsorption capacity } \\
(\mathrm{mg} / \mathrm{g})\end{array}$ & Reference \\
\hline Pine / TiO2 & 12.8 & (Zhao et al. 2021) \\
cotton/chitosan & 7.5 & (Rojas et al. 2018) \\
Immobilized corn cob & 112.49 & (Manzoor et al. 2019) \\
C-4-APD & 73.78 & this work \\
C-2-APZ & 61.34 & this work \\
\hline
\end{tabular}

5 binding data, the two equations are expressed as follows:

$6 \quad \frac{C_{\mathrm{e}}}{Q_{e}}=\frac{1}{k_{L} Q_{\max }}+\frac{C_{e}}{Q_{\max }}$

$7 \quad \ln \mathrm{Q}_{\mathrm{e}}=\ln \mathrm{k}_{\mathrm{F}}+\frac{1}{\mathrm{n}} \ln C_{e}$

where $\mathrm{Q}_{\mathrm{e}}(\mathrm{mg} / \mathrm{g})$ is the amount of $\mathrm{Cr}(\mathrm{VI})$ ions bound to the C-4-APD 和 C-2-APZ at equilibrium, $\mathrm{C}_{\mathrm{e}}(\mathrm{mg} / \mathrm{L})$ is the equilibrium concentration, and $Q_{\max }(\mathrm{mg} / \mathrm{g})$ is the apparent maximum adsorption capacity. $\mathrm{K}_{\mathrm{L}}$ is the Langmuir constant, $\mathrm{K}_{\mathrm{F}}$ and $1 / \mathrm{n}$ are

11 the Freundlich constants. The fits of Langmuir and Freundlich isothermal adsorption models for $\mathrm{Cr}(\mathrm{VI})$ ions adsorbed by C-4-APD and C-2-APZ were shown in Fig. 6B and C. The isotherm parameters of the two models were listed in Table 4. From the fitted curves, it can be seen that the correlation coefficients $\mathrm{R}^{2}(0.971$ and 0.967$)$ of the linear equations after fitting the Langmuir equation were closer to 1 than those of the Freundlich model, which proves that the Langmuir model can describe the experimental measured data 
1 more closely. In addition, the maximum adsorption capacities of C-4-APD and C-2-

2 APZ were calculated as $108.11 \mathrm{mg} / \mathrm{g}$ and $82.2 \mathrm{mg} / \mathrm{g}$ by taking the experimental data

3 into the equation of Langmuir model, which were different from the experimental

4 adsorption capacity. This was due to the formation of hydrogen bonds between the

5 groups in C-4-APD or C-2-APZ, which occupy the adsorption sites and make the actual

6 maximum adsorption capacity lower than the calculated value. Furthermore, the large

7 size of $\mathrm{Cr}_{2} \mathrm{O}_{7}^{2-}$ makes it difficult to enter the adsorption sites, thus limiting the

8 adsorption capacity of $\mathrm{Cr}_{2} \mathrm{O}_{7}{ }^{2-}$ (Fenti et al. 2020). These results demonstrate that the

9 adsorption of $\mathrm{Cr}(\mathrm{VI})$ ions by C-4-APD and C-2-APZ was the monolayer adsorption

10 process.

11 Table 4 Parameters for $\mathrm{Cr}(\mathrm{VI})$ ions adsorption by C-4-APD and C-2-APZ according to

12 different equilibrium models.

\begin{tabular}{ccccccc}
\hline Absorbent & \multicolumn{3}{c}{ Langmuir } & \multicolumn{3}{c}{ Freundlich } \\
\hline & $\mathrm{Q}_{\mathrm{m}}(\mathrm{mg} / \mathrm{g})$ & $\mathrm{k}_{\mathrm{L}}(\mathrm{mg} / \mathrm{L})$ & $\mathrm{R}^{2}$ & $1 / \mathrm{n}$ & $\mathrm{k}_{\mathrm{F}}((\mathrm{mg} / \mathrm{g}) /(\mathrm{L} / \mathrm{mg})) 1 / \mathrm{n}$ & $\mathrm{R}^{2}$ \\
\cline { 2 - 7 } C-4-APD & 108.11 & 0.00998 & 0.971 & 0.50244 & 4.9163 & 0.906 \\
C-4-APZ & 82.2 & 0.0141 & 0.967 & 0.43877 & 5.84634 & 0.9 \\
\hline
\end{tabular}

\subsubsection{Reusability studies}

Desorption and regeneration of adsorbent is one of the most important properties of adsorption separation technology. In this experiment, a thiourea-hydrochloric acid solution with a mass fraction of $2 \mathrm{wt} \%$ (the concentration of $\mathrm{HCl}$ was $0.5 \mathrm{~mol} / \mathrm{L}$ ) was chosen as the eluent. The mixed thiourea-hydrochloric acid solution can not only elute the $\mathrm{Cr}(\mathrm{VI})$ ions from the binding sites, but also thiourea can reduce $\mathrm{Cr}(\mathrm{VI})$ to the less toxic $\mathrm{Cr}$ (III) under acidic conditions. To investigate the reusability and stability of C-4APD and C-2-APZ, we performed six adsorption-desorption processes using the same 
1 C-4-APD and C-2-APZ, and the adsorption amounts of the six experiments were in Fig.

2 7. As can be seen from the figure, the adsorption capacities of C-4-APD and C-2-APZ

3 for $\mathrm{Cr}(\mathrm{VI})$ ions with multiple reuses did not change evidently and remained above $90 \%$

4 and $80 \%$, which proved that C-4-APD and C-2-APZ have good reusability and stability.

5 Which was due to the excellent flexibility of degreasing cotton as a substrate, the

6 adsorption sites were not easily destroyed and deformed. Furthermore, the adsorption

$7 \quad$ sites encapsulated by hydrogen bonds can replace the destroyed adsorption sites to some

8 extent after multiple washes. Thus, the multiple adsorption-desorption process has less

9 effect on the adsorption capacity of C-4-APD and C-2-APZ.

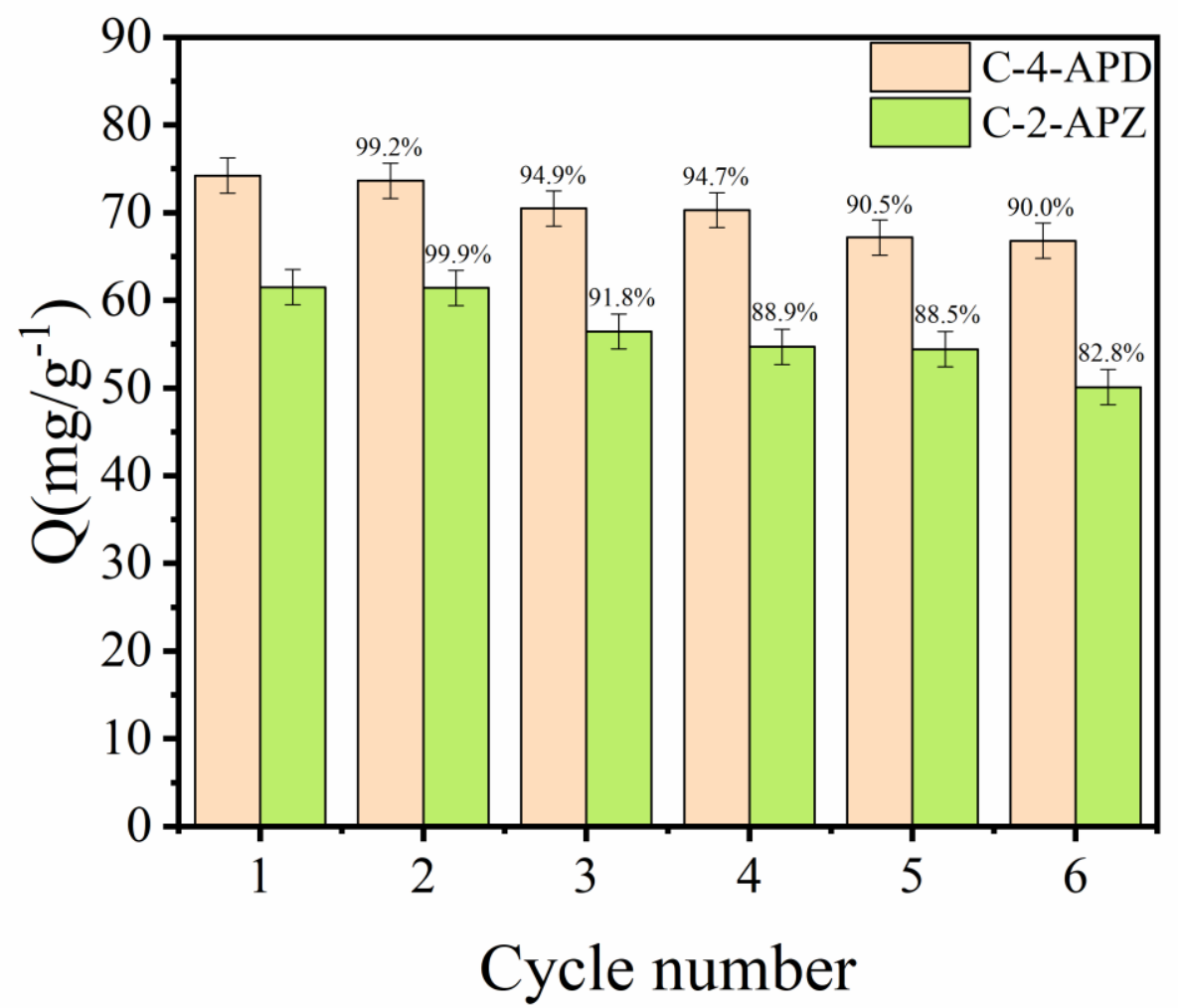

11 Fig. 7 Regeneration of C-4-APD and C-2-APZ.

\section{Conclusions}

13 In summary, 4-aminopyridine and 2-aminopyrazine were successfully introduced 
1 to the surface of cotton fiber and used to remove $\mathrm{Cr}(\mathrm{VI})$ ions from aqueous solution in

2 this study. SEM, FT-IR and XPS that a large number of amino, pyridine and pyrazine

3 groups were introduced to the surface of cotton fiber after modification by 4-

4 aminopyridine and 2-aminopyrazine. The $\mathrm{Cr}(\mathrm{VI})$ ions on the modified cotton fiber

5 adsorption was mainly achieved by electrostatic interactions between the protonated

6 functional groups on the adsorbent and the $\mathrm{Cr}(\mathrm{VI})$ anions. The maximum adsorption

7 capacities of C-4-APD and C-2-APZ were $73.78 \mathrm{mg} / \mathrm{g}$ and $61.34 \mathrm{mg} / \mathrm{g}$, respectively, at

8 the optimum $\mathrm{pH}$ of 2 and an initial concentration of $200 \mathrm{mg} / \mathrm{g}$. Kinetic studies showed

9 that the adsorption process followed the pseudo-second-order kinetic model indicating

10 that the adsorption process was mainly controlled by physicochemical adsorption. The

11 adsorption isotherm analysis showed that the Langmuir model was in good agreement

12 with the adsorption equilibrium data and the adsorption was the monolayer adsorption

13 process. In addition, the adsorption capacities of adsorbents didn't significantly

14 decrease after six times of repeated use, and they decreased gradually in subsequent

15 runs to $90 \%$ and $80 \%$, respectively. These results indicate the potential application of

16 4-aminopyridine and 2-aminopyrazine modified cotton fibers in the removal of $\mathrm{Cr}(\mathrm{VI})$

17 ions from aqueous solutions.

18 Acknowledgments:

19 The authors appreciate the financial support from the Key Research and

20 Development Plan of Hubei Province(2020BCB068).

21 Author contributions Conceptualization: ZYH, PW, SHC, XT; Methodology: ZYH;

22 Investigation: ZYH, PW; Formal analysis: ZYH, PW; Writing-original draft 
1 preparation: ZYH; Writing — review and editing: ZYH, PW, XZ, YKY, LF, SHC, XT;

2 Funding acquisition: SHC, XT, LXW; Resources: SHC, XT, LXW; Supervision: ZYH,

$3 \quad$ PW, SHC, XT.

4 Funding the Key Research and Development Plan of Hubei Province (2020BCB068).

\section{$5 \quad$ Declarations}

\section{$6 \quad$ Conflict of interest}

$7 \quad$ The authors declare that they have no conflicts of interest to declare.

Ethical Standards

This article does not contain any studies with human participants or animals performed by any of theauthors.

Informed consent None.

\section{References}

Bao S, Liu H, Liu Y, Yang W, Wang Y, Yu Y, Sun Y, Li K (2020) Amino-functionalized graphene oxide-supported networked Pd-Ag nanowires as highly efficient catalyst for reducing $\mathrm{Cr}(\mathrm{VI})$ in industrial effluent by formic acid. Chemosphere 257: 127245. https://doi.org/10.1016/j.chemosphere.2020.127245.

Bayramoglu G, Akbulut A, Arica MY (2016) Aminopyridine modified Spirulina platensis biomass for chromium(VI) adsorption in aqueous solution. Water Sci Technol 74: 914-926. https://doi.org/10.2166/wst.2016.281.

Eliodorio KP, Andolfatto VS, Martins MRG, De Sá BP, Umeki ER, De Araújo Morandim-Giannetti A (2017) Treatment of chromium effluent by adsorption on chitosan activated with ionic liquids. Cellulose 24: 2559-2570. https://doi.org/10.1007/s10570-017-1264-3.

Fenti A, Chianese S, Iovino P, Musmarra D, Salvestrini S (2020) Cr(VI) Sorption from Aqueous Solution: A Review. Applied Sciences 10: 6477. 
https://doi.org/10.3390/app10186477.

Geng T, Ma L, Chen G, Zhang C, Zhang W, Niu Q (2020) Fluorescent conjugated microporous polymers containing pyrazine moieties for adsorbing and fluorescent sensing of iodine. Environ Sci Pollut Res Int 27: 20235-20245. https://doi.org/10.1007/s11356-019-06534-8.

Hu Y, Zhang J, Yu C, Li Q, Dong F, Wang G, Guo Z (2014) Synthesis, characterization, and antioxidant properties of novel inulin derivatives with amino-pyridine $\begin{array}{lllll}\text { group. } & \text { Int } & \mathrm{J} & \text { Biol } & \text { 44-49. }\end{array}$ https://doi.org/10.1016/j.ijbiomac.2014.06.024.

Kimbrough DE, Cohen Y, Winer AM, Creelman L, Mabuni C (1999) A Critical Assessment of Chromium in the Environment. Critical Reviews in Environmental Science and Technology 29: 1-46. https://doi.org/10.1080/10643389991259164.

Kooshki F, Tutunchi H, Vajdi M, Karimi A, Niazkar HR, Shoorei H, Pourghassem Gargari B (2021) A Comprehensive insight into the effect of chromium supplementation on oxidative stress indices in diabetes mellitus: A systematic review. Clin Exp Pharmacol Physiol 48: 291-309. https://doi.org/10.1111/1440$\underline{1681.13462 .}$.

Li LL, Feng XQ, Han RP, Zang SQ, Yang G (2017) Cr(VI) removal via anion exchange on a silver-triazolate MOF. J Hazard Mater 321: 622-628. https://doi.org/10.1016/j.jhazmat.2016.09.029.

Li Y, Zhu H, Zhang C, Cheng M, He H (2018) PEI-grafted magnetic cellulose for Cr(VI) removal from aqueous solution. Cellulose 25: 4757-4769. https://doi.org/10.1007/s10570-018-1868-2.

Liang X, Liang B, Wei J, Zhong S, Zhang R, Yin Y, Zhang Y, Hu H, Huang Z (2020) A cellulose-based adsorbent with pendant groups of quaternary ammonium and amino for enhanced capture of aqueous Cr(VI). Int J Biol Macromol 148: 802810. https://doi.org/10.1016/j.ijbiomac.2020.01.184.

Long B, Ye J, Ye Z, He J, Luo Y, Zhao Y, Shi J (2020) Cr(VI) removal by Penicillium 
oxalicum SL2: Reduction with acidic metabolites and form transformation in $\begin{array}{llll}\text { the } & \text { mycelium. } & \text { 253: } & \end{array}$ https://doi.org/10.1016/j.chemosphere.2020.126731.

Lu H, Wu F, Yang Y, Li S, Hua Y, Zhu L (2020) Hole transport materials based on a twisted molecular structure with a single aromatic heterocyclic core to boost the performance of conventional perovskite solar cells. Journal of Materials Chemistry C 8: 13415-13421. https://doi.org/10.1039/d0tc03404e.

Manzoor Q, Sajid A, Hussain T, Iqbal M, Abbas M, Nisar J (2019) Efficiency of immobilized Zea mays biomass for the adsorption of chromium from simulated media and tannery wastewater. Journal of Materials Research and Technology 8: 75-86. https://doi.org/10.1016/j.jmrt.2017.05.016.

Moradi F, Maleki V, Saleh-Ghadimi S, Kooshki F, Pourghassem Gargari B (2019) Potential roles of chromium on inflammatory biomarkers in diabetes: A Systematic. Clin Exp Pharmacol Physiol 46: 975-983. https://doi.org/10.1111/1440-1681.13144.

Park SH, Shin SS, Park CH, Jeon S, Gwon J, Lee SY, Kim SJ, Kim HJ, Lee JH (2020) Poly(acryloyl hydrazide)-grafted cellulose nanocrystal adsorbents with an excellent Cr(VI) adsorption capacity. J Hazard Mater 394: 122512. https://doi.org/10.1016/j.jhazmat.2020.122512.

Peng X, Yan Z, Hu L, Zhang R, Liu S, Wang A, Yu X, Chen L (2020) Adsorption behavior of hexavalent chromium in aqueous solution by polyvinylimidazole modified cellulose. Int J Biol Macromol 155: 1184-1193. https://doi.org/10.1016/j.ijbiomac.2019.11.086.

Rojas SI, Duarte DC, Mosquera SD, Salcedo F, Hinestroza JP, Husserl J (2018) Enhanced biosorption of $\mathrm{Cr}(\mathrm{VI})$ using cotton fibers coated with chitosan - role of ester bonds. Water Sci Technol 78: 476-486. https://doi.org/10.2166/wst.2018.284.

Sharma AK, Devan RS, Arora M, Kumar R, Ma Y-R, Babu JN (2018) Reductive-coprecipitated cellulose immobilized zerovalent iron nanoparticles in ionic 
liquid/water for $\mathrm{Cr}(\mathrm{VI})$ adsorption. Cellulose 25: 5259-5275. https://doi.org/10.1007/s10570-018-1932-y.

Simonin J-P (2016) On the comparison of pseudo-first order and pseudo-second order rate laws in the modeling of adsorption kinetics. Chemical Engineering Journal 300: 254-263. https://doi.org/10.1016/j.cej.2016.04.079.

Singh P, Chowdhuri DK (2017) Environmental Presence of Hexavalent but Not Trivalent Chromium Causes Neurotoxicity in Exposed Drosophila melanogaster. Mol Neurobiol 54: 3368-3387. https://doi.org/10.1007/s12035-016-9909-z.

Sun Y, Liu X, Lv X, Wang T, Xue B (2021) Synthesis of novel lignosulfonate-modified graphene hydrogel for ultrahigh adsorption capacity of $\mathrm{Cr}(\mathrm{VI})$ from wastewater. Journal of Cleaner Production 295: 126406. https://doi.org/https://doi.org/10.1016/j.jclepro.2021.126406.

Vakili M, Deng S, Li T, Wang W, Wang W, Yu G (2018) Novel crosslinked chitosan for enhanced adsorption of hexavalent chromium in acidic solution. Chemical Engineering Journal 347: 782-790. https://doi.org/10.1016/j.cej.2018.04.181.

Wang P, Yin Y, Xu J, Chen S, Wang H (2019) Facile synthesis of Cu2+-immobilized imprinted cotton for the selective adsorption of bovine hemoglobin. Cellulose 27: 867-877. https://doi.org/10.1007/s10570-019-02816-z.

Wei Y, Chen W, Liu C, Wang H (2021) Facial Synthesis of Adsorbent from Hemicelluloses for $\mathrm{Cr}(\mathrm{VI})$ Adsorption. Molecules 26: 1443. https://doi.org/10.3390/molecules26051443.

Wu Y, Zhang S, Guo X, Huang HJBT (2008) Adsorption of chromium (III) on lignin. 99: 7709-7715.

Xie B, Shan C, Xu Z, Li X, Zhang X, Chen J, Pan B (2017) One-step removal of Cr(VI) at alkaline $\mathrm{pH}$ by $\mathrm{UV} /$ sulfite process: Reduction to $\mathrm{Cr}(\mathrm{III})$ and in situ $\mathrm{Cr}$ (III) precipitation. Chemical Engineering Journal 308: 791-797. https://doi.org/10.1016/j.cej.2016.09.123.

Xu X, Gao B, Jin B, Yue Q (2016) Removal of anionic pollutants from liquids by biomass materials: A review. Journal of Molecular Liquids 215: 565-595. 
2 Yao F, Jia M, Yang Q, Luo K, Chen F, Zhong Y, He L, Pi Z, Hou K, Wang D, Li X 3 (2020) Electrochemical Cr(VI) removal from aqueous media using titanium as anode: Simultaneous indirect electrochemical reduction of $\mathrm{Cr}(\mathrm{VI})$ and in-situ $\begin{array}{lllll}\text { precipitation } & \text { of } & \mathrm{Cr}(\mathrm{III}) . & \text { Chemosphere } & 260 \text { : }\end{array}$ https://doi.org/10.1016/j.chemosphere.2020.127537.

Zhang S, Chen H, Zhang S, Kai C, Jiang M, Wang Q, Zhou Z (2019) Polyethylenimine grafted H2O2-oxidized cellulose membrane as a novel biosorbent for $\mathrm{Cr}(\mathrm{VI})$ adsorption and detoxification from aqueous solution. Cellulose 26: 3437-3453. https://doi.org/10.1007/s10570-019-02325-Z.

Zhao J, Boada R, Cibin G, Palet C (2021) Enhancement of selective adsorption of Cr species via modification of pine biomass. Sci Total Environ 756: 143816. https://doi.org/10.1016/j.scitotenv.2020.143816.

Zhao J, Zhang X, He X, Xiao M, Zhang W, Lu C (2015) A super biosorbent from dendrimer poly(amidoamine)-grafted cellulose nanofibril aerogels for effective removal of $\mathrm{Cr}(\mathrm{vi})$. Journal of Materials Chemistry A 3: 14703-14711. https://doi.org/10.1039/c5ta03089g. 


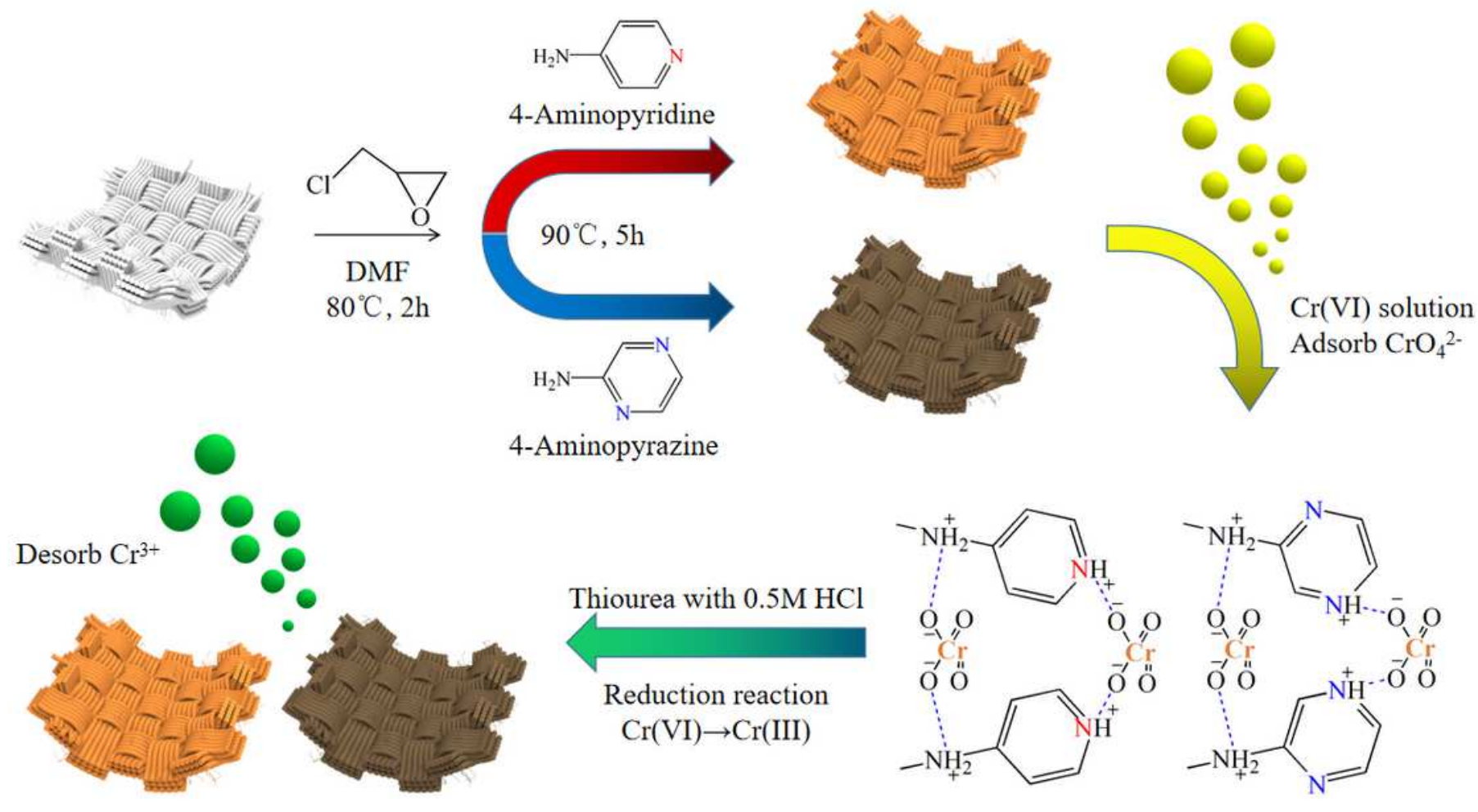

Figure 1

Schematic illustration of the C-4-APD and C-2-APZ preparation process. 

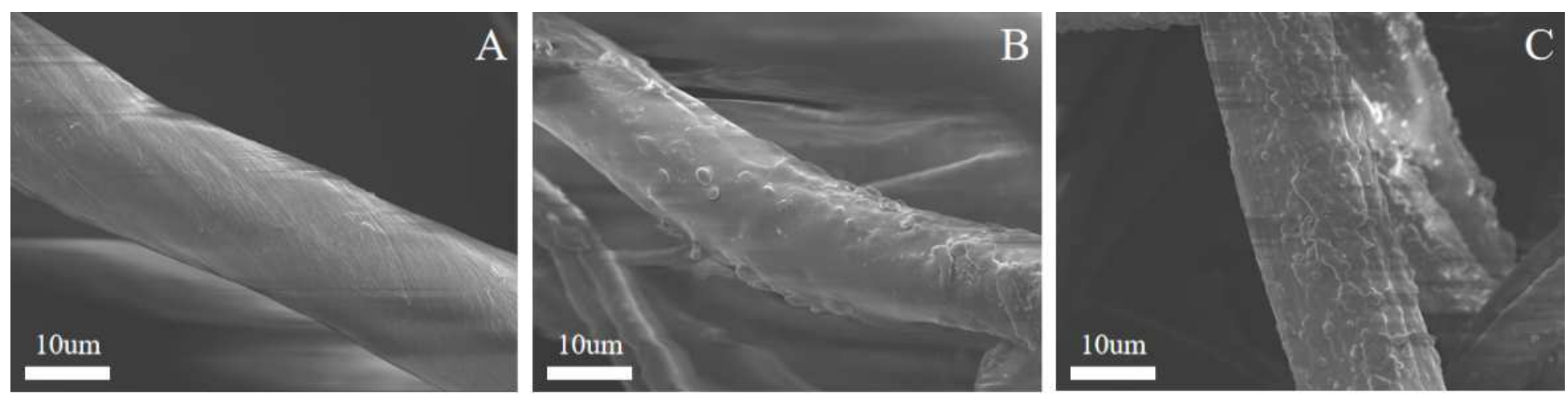

Figure 2

SEM images of the degreasing cotton (A), C-4-APD (B) and C-2-APZ (C). 


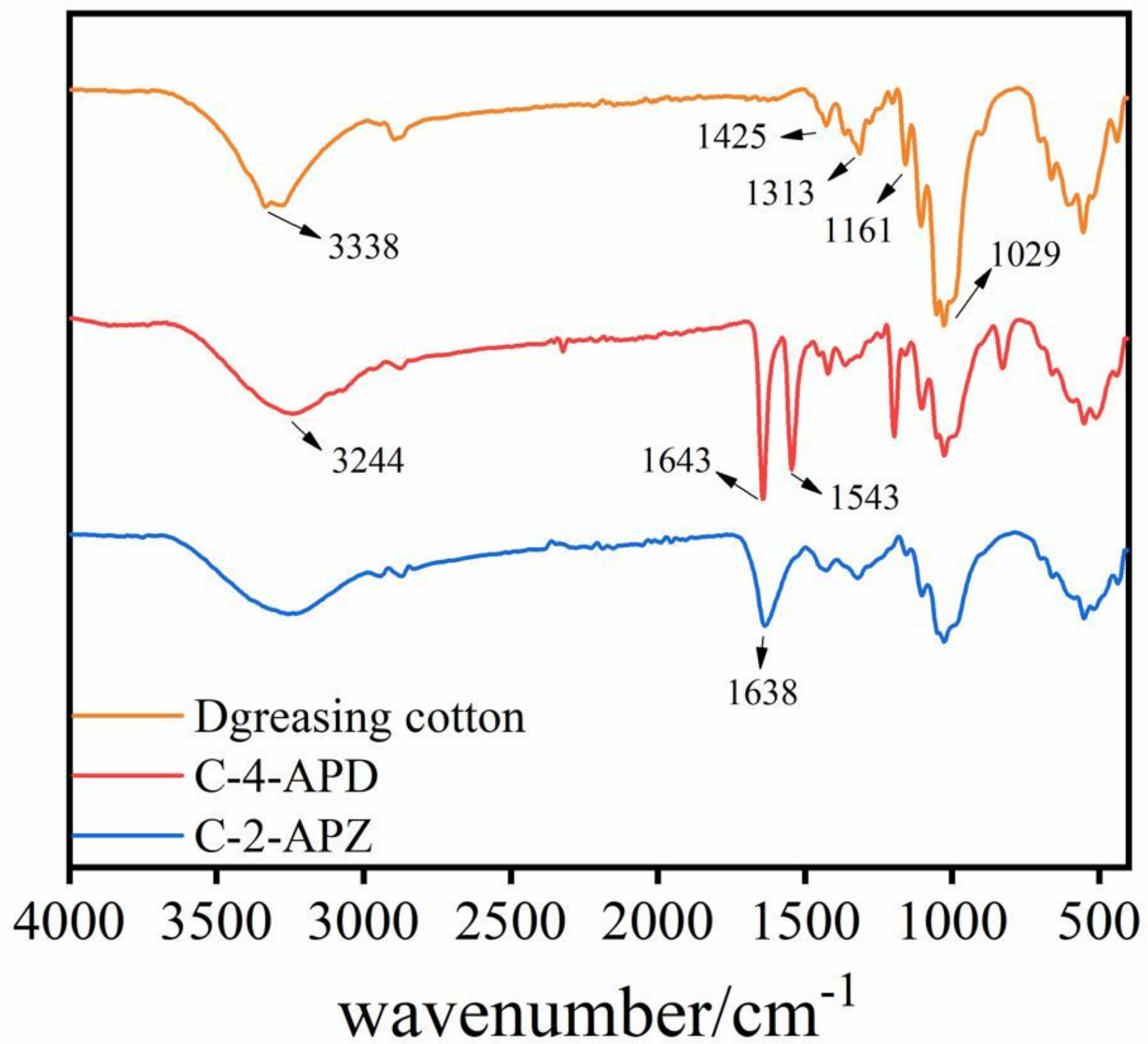

Figure 3

FTIR spectra of degreasing cotton, C-4-APD and C-2-APZ. 


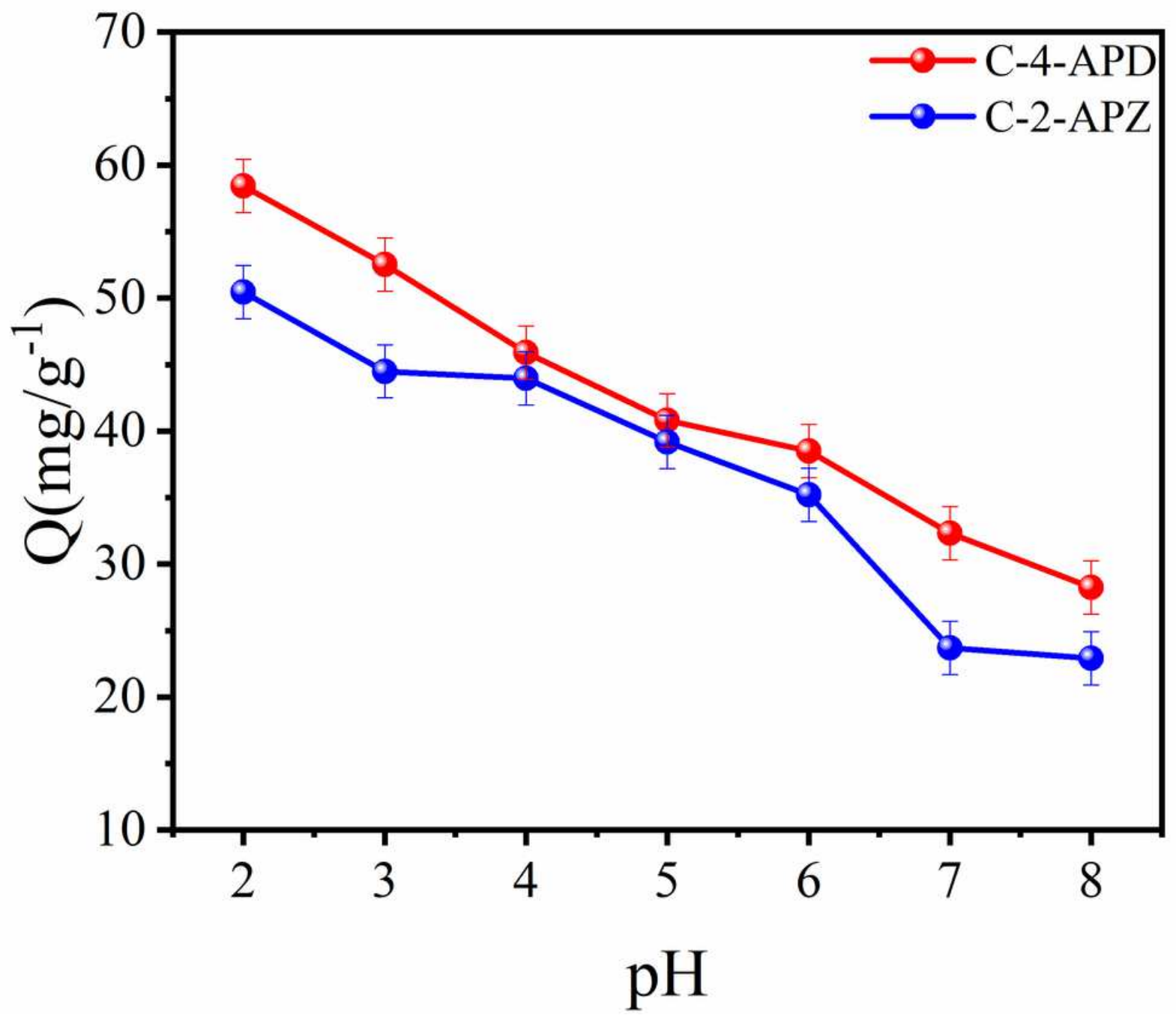

Figure 4

Effect of the $\mathrm{pH}$ value on the adsorption of $\mathrm{Cr}(\mathrm{VI})$ ions by C-4-APD and C-2-APZ. 

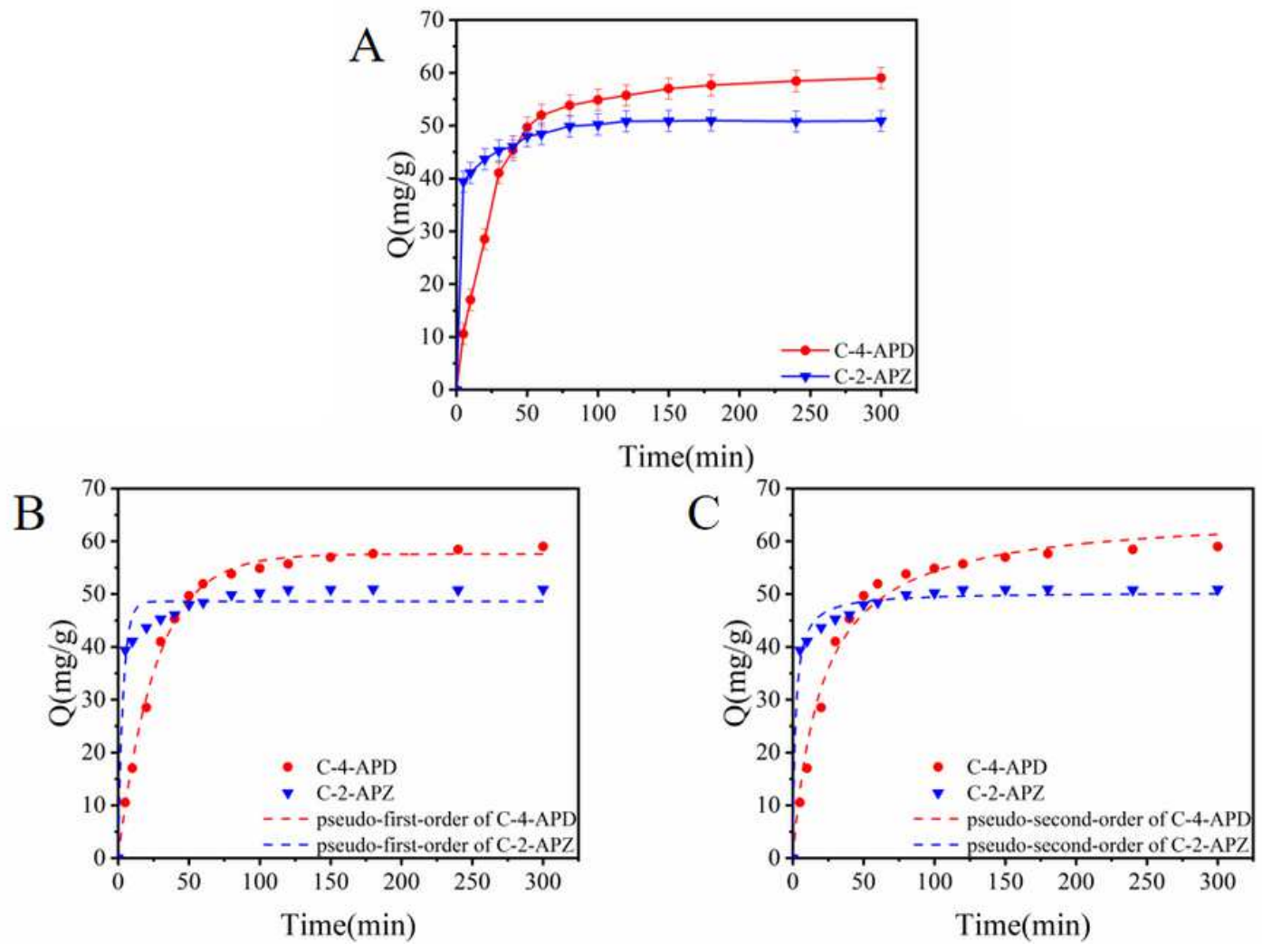

Figure 5

Effect of contact time on the $\mathrm{Cr}(\mathrm{VI})$ ions adsorption capacity of C-4-APD and C-2-APZ(A); The curve fitting with pseudo-first-order(B) and pseudo-second-order kinetics model(C).
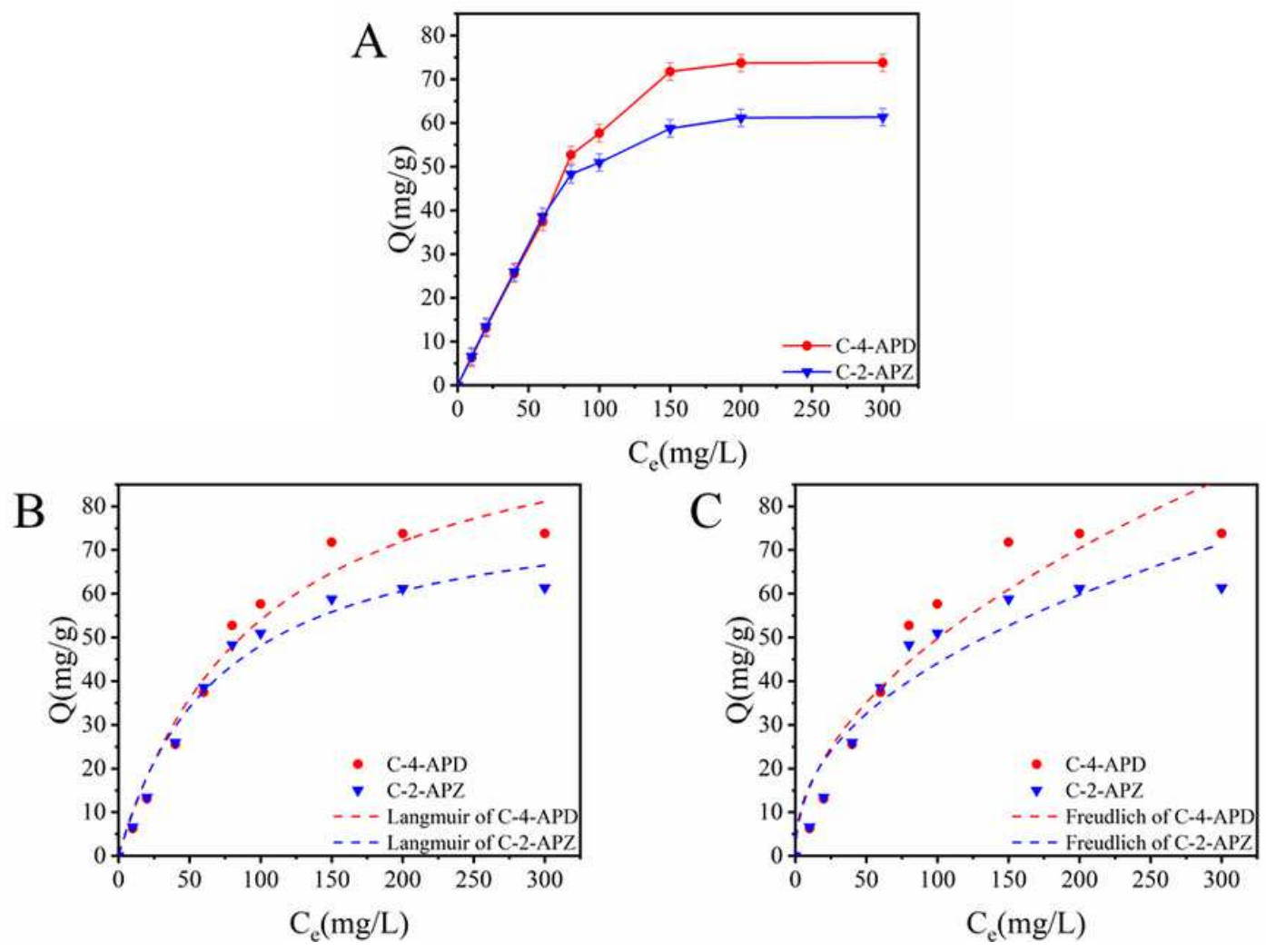
Figure 6

$\mathrm{Cr}(\mathrm{VI})$ ions adsorption isotherms for the C-4-APD and C-2-APZ(A); The curve fitting with the Langmuir(B) and Freundlich model(C).

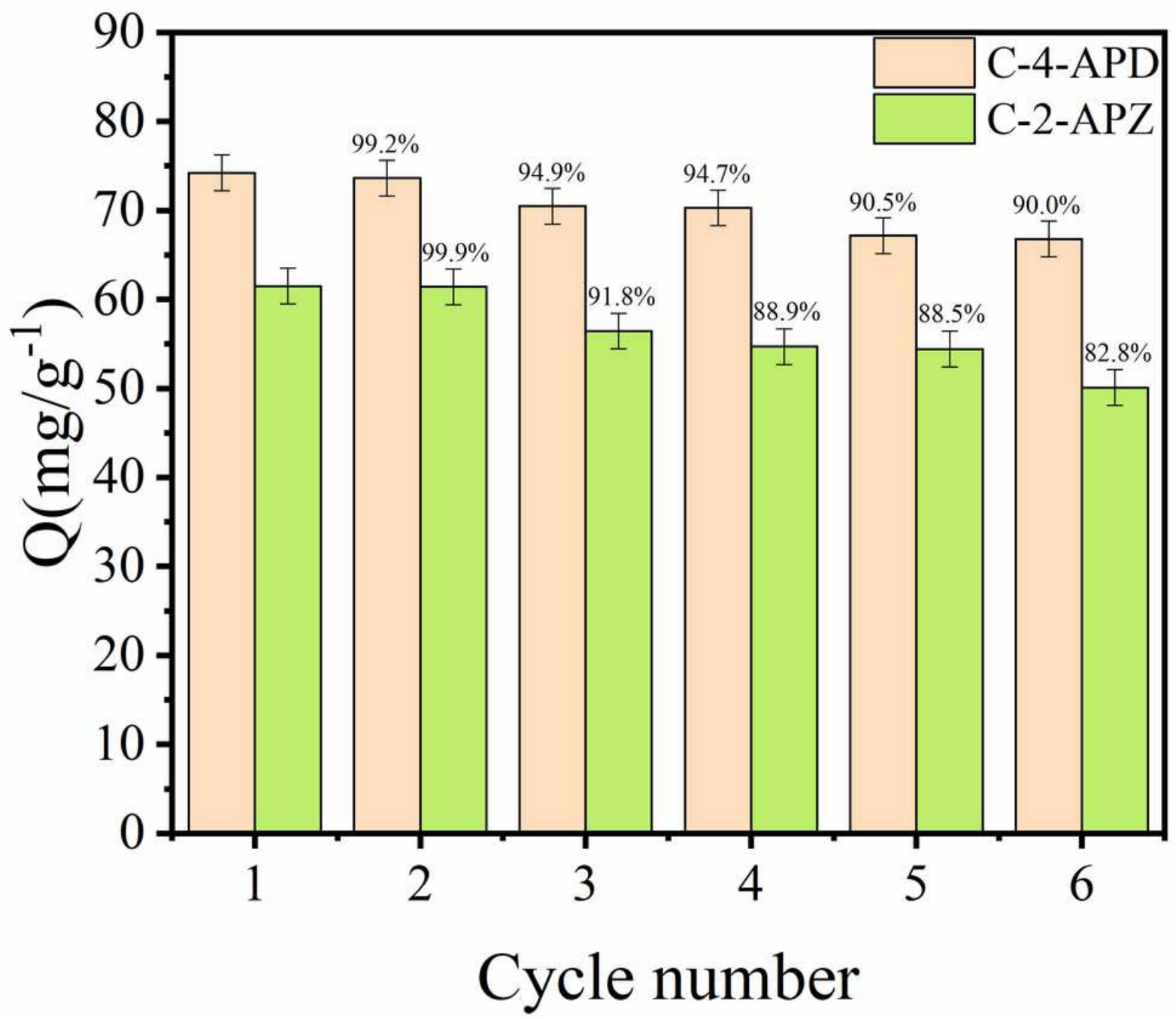

Figure 7

Regeneration of C-4-APD and C-2-APZ. 